\section{JURNAL EKONOMI EFEKTIF}

ISSN : $2622-8882$, E-ISSN : 2622-9935

Jurnal Ekonomi Efektif, Vol. 3, No. 3, April 2021

@Prodi Manajemen Fakultas Ekonomi Universitas

Pamulang

\title{
PENGARUH KEPEMIMPINAN KEPALA SEKOLAH TERHADAP KINERJA GURU PADA SMP BINA BANGSA DI TANGERANG
}

\author{
Indra Januar Rukmana \\ Universitas Pamulang, Tangerang Selatan, Banten, Indonesia \\ dosen02585@unpam.ac.id
}

Manuskrip: Mar-2021 Ditinjau: Mar-2021; Diterima: Mar-2021; Online: Apr-2021; Diterbitkan: Apr-2021

\begin{abstract}
ABSTRAK
Penelitian ini bertujuan untuk mengetahui pengaruh Kepemimpinan Kepala Sekolah terhadap kinerja Guru pada SMP Bina Bangsa di Tangerang. Metode yang digunakan adalah explanatory research dengan sampel sebanyak 37 responden. Teknik analisis menggunakan analisis statistik dengan pengujian regresi, korelasi, determinasi dan uji hipotesis. Hasil penelitian ini variabel Kepemimpinan Kepala Sekolah diperoleh nilai rata-rata skor sebesar 3,808 dengan kriteria baik. Variabel kinerja Guru diperoleh nilai rata-rata skor sebesar 3,889 dengan kriteria baik. Kepemimpinan Kepala Sekolah berpengaruh positif dan signifikan terhadap kinerja Guru dengan nilai persamaan regresi $\mathrm{Y}=8,442+0,800 \mathrm{X}$, dan nilai koefisien korelasi 0,821 atau memiliki tingkat hubungan yang sangat kuat dengan nilai determinasi $67,5 \%$. Uji hipotesis diperoleh signifikansi $0,000<0,05$.
\end{abstract}

Kata Kunci: Kepemimpinan Kepala Sekolah, Kinerja Guru.

\begin{abstract}
This study aims to determine the effect of principal leadership on teacher performance at SMP Bina Bangsa in Tangerang. The method used is explanatory research with a sample of 37 respondents. The analysis technique uses statistical analysis with regression testing, correlation, determination and hypothesis testing. The results of this study, the Principal Leadership variable, obtained an average score of 3.808 with good criteria. Teacher performance variables obtained an average score of 3.889 with good criteria. Principal leadership has a positive and significant effect on teacher performance with a regression equation value of $Y=8.442+0.800 X$, and a correlation coefficient value of 0.821 or has a very strong level of relationship with a determination value of $67.5 \%$. Hypothesis testing obtained a significance of $0.000<0.05$.
\end{abstract}

Keywords: Principal Leadership, Teacher Performance. 


\section{PENDAHULUAN}

\section{A. Latar Belakang Masalah}

Perkembangan zaman yang semakin modern pada era globalisasi seperti sekarang ini menuntut adanya sumber daya yang berkualitas tinggi. Pengaruh sumber daya manusia secara global disadari maupun tidak akan sampai kepada setiap bangsa di dunia. Peningkatan sumber daya manusia merupakan persyaratan mutlak untuk mencapai tujuan pembangunan. Salah satu wahana untuk meningkatkan kualitas sumber daya manusia tersebut adalah pendidikan.

Manajemen sumber daya manusia adalah pencapaian tujuan (organisasi) yang sudah ditentukan sebelumnya dengan menggunakan bantuan orang lain. Globalisasi manajemen adalah fakta kehidupan. Globalisasi mengacu pada sikap baru, terbuka mengenai mempraktekan manajemen secara internasional. Sikap ini menggabungkan keingintahuan mengenai dunia diluar batas nasional dengan kemauan untuk mengembangkan kemampuan guna beradaptasi dalam ekonomi global. Salah satu hal yang mendasar dalam perkembangan dan kemajuan pembangunan bangsa adalah sumber daya manusia yang mendukung proses pembangunan itu sendiri. Jika bangsa Indonesia ingin berkiprah dalam percaturan global maka langkah pertama yang harus dilakukan adalah menata sumber daya manusia, baik dari aspek intelektual, emosional, spiritual, kreatifitas, moral maupun tanggung jawabnya. Penataan sumber daya manusia tersebut perlu diupayakan secara bertahap dan berkesinambungan melalui sistem pendidikan yang berkualitas, baik pada jalur pendidikan formal, nonformal dan informal, mulai dari pendidikan dasar sampai pendidikan tinggi. Berbagai indikator menunjukan bahwa pendidikan yang ada belum mampu menghasilkan sumber daya yang sesuai dengan perkembangan masyarakat dan kebutuhan pembangunan.

Penerapan sumber daya manusia di SMP Bina Bangsa di Tangerang belum optimal baik dalam persyaratan pendidikan yang belum memenuhi standar serta penempatan kerja yang tidak sesuai dengan pendidikan yang melatarbelakanginya, sehingga peran pemimpin sangat penting untuk turut intervensi dalam penerapan sumber daya manusia yang ada di SMP Bina Bangsa di Tangerang.

Pemimpin merupakan seorang yang memiliki suatu program yang berperilaku secara bersama-sama dengan anggota-anggota kelompok dengan mempergunakan cara atau gaya tertentu, sehingga kepemimpinan mempunyai peranan sebagai kekuatan dinamik yang mendorong, memotivasi dan mengkoordinasikan organisasi dalam mencapai tujuan yang telah ditetapkan. Pentingnya kepemimpinan Kepala Sekolah untuk melakukan berbagai cara dalam kegiatan mempengaruhi atau memberi motivasi kepada guru agar melakukan tindakan-tindakan yang selalu terarah terhadap pencapaian tujuan sekolah. Gaya kepemimpinan merupakan suatu cara pemimpin untuk mempengaruhi bawahannya yang dinyatakan dalam bentuk pola tingkah laku atau kepribadian. Menurut Kartini Kartono (2008: 34) "Gaya kepemimpinan adalah sifat, kebiasaan, tempramen, watak dan kepribadian yang membedakan seorang pemimpin dalam berinteraksi dengan oramg lain".

Hasil wawancara di lingkup SMP Bina Bangsa di Tangerang mengenai kepemimpinan SMP Bina Bangsa memiliki pernyataan yang sangat signifikan.

Dari hasil observasi Kepemimpinan di SMP Bina Bangsa di Tangerang masih dikatakan belum optimal, karena pemimpin memiliki sifat tidak tegas, lamban dalam mengambil keputusan disetiap permasalahan, dan tidak berani membuat peraturan baru sesuai dengan kebutuhan di lingkungan sekolah. Sehingga SMP Bina Bangsa di Tangerang menjadi lebih baik. Baik bagi pendidik, tenaga pendidik maupun siswanya.

Kinerja guru dalam lembaga pendidikan tidak terlepas dari seorang kepala sekolah 
yang memimpin lembaga itu sendiri. Didalam suatu lembaga pendidikan dibutuhkan seorang pemimpin yang dapat memberikan semangat kerja kepada bawahannya untuk senantiasa produktif dan juga mampu menciptakan lingkungan sekolah yang kondusif, sebab keberadaan seorang pemimpin dalam suatu lembaga pendidikan dirasakan sangat mutlak untuk menjadi nahkoda bagi para bawahannya.

Kinerja guru adalah hasil kerja yang dapat dicapai oleh seorang guru di lembaga pendidikan atau sekolah sesuai dengan tugas dan tanggung jawabnya dalam mencapai tujuan pendidikan. Kinerja guru dapat dilihat dan diukur berdasarkan spesifikasi atau kriteria kompetensi yang harus dimiliki oleh setiap guru. Kinerja guru menurut Supardi (2014:54) merupakan kemampuan seorang guru dalam melaksanakan tugas pembelajaran di sekolah dan bertanggung jawab atas peserta didik dibawah bimbingannya dengan meningkatkan prestasi belajar peserta didik.

Kinerja guru di SMP Bina Bangsa di Tangerang masih terbilang lemah dikarenakan ada beberapa faktor, diantaranya; tidak disiplin dalam menjalankan tugasnya, menyepelekan tugas pokok serta fungsinya sebagai guru dan guru menjadi tidak patuh terhadap peraturan yang sudah ada.

Di SMP Bina Bangsa di Tangerang pelaksanaan tugas mendidik, guru memiliki sifat dan prilaku yang berbeda, ada yang bersemangat dan penuh tanggung jawab, juga ada guru yang melakukan pekerjaannya itu tanpa dilandasi rasa tanggung jawab. Kondisi seperti itulah yang menjadi permasalahan disetiap lembaga pendidikan formal. Dengan adanya guru yang mempunyai kinerja rendah, sekolah akan sulit mencapai seperti yang diharapkan.

Sekolah berada di tengah-tengah masyarakat dan dapat di katakan berfungsi sebagai pisau bermata dua. Mata yang pertama adalah menjaga kelastarian nilai-nilai positif yang ada dalam masyarakat agar pewarisan nilai-nilai masyarakat berlangsung dengan baik. Mata yang kedua adalah sebagai lembaga yang mendorong perubahan nilai dan tradisi sesuai dengan kemajuan dan tuntutan kehidupan serta pembangunan.

SMP Bina Bangsa adalah sekolah yang memiliki dedikasi tinggi dalam dunia pendidikan, yang memiliki visi dan misi sangat banyak untuk memajukan dunia pendidikan terutama menciptakan siswa dan siswi Qur'ani serta berakhlaqul karimah sesuai ajaran islam. Berdasarkan uraian diatas maka penulis tertarik untuk menulis penelitian ilmiah dengan judul "Hubungan Kepemimpinan Kepala Sekolah Terhadap Kinerja Guru di SMP Bina Bangsa di Tangerang”.

\section{B. Rumusan Masalah}

1. Bagaimana Kepemimpinan Kepala Sekolah pada SMP Bina Bangsa di Tangerang?.

2. Bagaimana kinerja Guru pada SMP Bina Bangsa di Tangerang ?.

3. Adakah pengaruh antara Kepemimpinan Kepala Sekolah terhadap kinerja Guru pada SMP Bina Bangsa di Tangerang ?.

\section{Tujuan Penelitian}

1. Untuk mengetahui kondisi Kepemimpinan Kepala Sekolah pada SMP Bina Bangsa di Tangerang.

2. Untuk mengetahui kondisi kinerja Guru pada SMP Bina Bangsa di Tangerang.

3. Untuk mengetahui pengaruh antara Kepemimpinan Kepala Sekolah terhadap kinerja Guru pada SMP Bina Bangsa di Tangerang. 


\section{METODE PENELITIAN}

\section{Populasi}

Populasi dalam penelitian ini berjumlah 37 responden Guru SMP Bina Bangsa di Tangerang

2. Sampel

Teknik pengambilan sampling dalam penelitian ini adalah sampel jenuh, dimana semua anggota populasi dijadikan sebagai sampel. Dengan demikian sampel dalam penelitian ini sampel yang digunakan berjumlah 37 responden.

\section{Jenis Penelitian}

Jenis penelitian yang dipakai adalah asosiatif, dimana tujuannya adalah untuk mengetahui atau mencari keterhubungan antara variabel independen terhadap variabel dependennya

\section{Metode Analisis Data}

Dalam menganalisis data digunakan uji validitas, uji reliabilitas, analisis regresi linier sederhana, analisis koefisien korelasi, analisis koefisien determinasi dan pengujian hipotesis.

\section{HASIL PENELITIAN DAN PEMBAHASAN}

\section{Analisis Deskriptif}

Pada pengujian ini digunakan untuk mengetahui skor minimum dan maksimum skor tertinggi, ratting score dan standar deviasi dari masing-masing variabel. Adapun hasilnya sebagai berikut:

Tabel 1. Hasil Analisis Descriptive Statistics

Descriptive Statistics

\begin{tabular}{lr|r|r|r|r} 
& N & Minimum & Maximum & \multicolumn{1}{c}{ Mean } & \multicolumn{1}{c}{ Std. Deviation } \\
\hline $\begin{array}{l}\text { Kepemimpinan Kepala } \\
\text { Sekolah (X) }\end{array}$ & 80 & 28 & 44 & 34.00 & 4.016 \\
\hline Kinerja Guru (Y) & 80 & 29 & 49 & 38.11 & 4.183 \\
\hline Valid N (listwise) & 80 & & & &
\end{tabular}

Kepemimpinan Kepala Sekolah diperoleh varians minimum sebesar 30 dan varians maximum 49 dengan ratting score sebesar 3,808 dengan standar deviasi 4,443. Skor ini termasuk pada rentang sakala 3,40 - 4,19 dengan kriteria baik atau setuju.

Kinerja Guru diperoleh varians minimum sebesar 29 dan varians maximum 50 dengan ratting score sebesar 3,889 dengan standar deviasi 4,326. Skor ini termasuk pada rentang sakala 3,40 - 4,19 dengan kriteria baik atau setuju.

\section{Analisis Verifikatif.}

Pada analisis ini dimaksudkan untuk mengetahui pengaruh variabel independen terhadap variabel dependen. Adapun hasil pengujian sebagai berikut:

\section{a. Analisis Regresi Linier Sederhana}

Uji regresi ini dimaksudkan untuk mengetahui perubahan variabel dependen jika variabel independen mengalami perubahan. Adapun hasil pengujiannya sebagai berikut:

\begin{tabular}{lr|r|r|r|r}
\multicolumn{7}{c}{ Tabel 2. Hasil Pengujian Regresi Linier Sederhana } \\
Model & \multicolumn{2}{c}{$\begin{array}{l}\text { Coefficientsa } \\
\text { Unstandardized } \\
\text { Coefficients }\end{array}$} & $\begin{array}{c}\text { Standardized } \\
\text { Coefficients }\end{array}$ & & \\
& $\mathrm{B}$ & Std. Error & Beta & \multicolumn{1}{c}{$\mathrm{t}$} & \multicolumn{1}{c}{ Sig. } \\
\hline 1 (Constant) & 10.945 & 2.589 & & 4.227 & .000 \\
\hline Motivasi $(\mathrm{X})$ & .799 & .076 & .767 & 10.564 & .000 \\
\hline
\end{tabular}


Berdasarkan hasil pengujian pada tabel di atas, diperoleh persamaan regresi $\mathrm{Y}$ $=8,442+0,800 \mathrm{X}$. Dari persamaan tersebut dijelaskan sebagai berikut:

1) Konstanta sebesar 8,442 diartikan jika Kepemimpinan Kepala Sekolah tidak ada, maka telah terdapat nilai kinerja Guru sebesar 8,442 point.

2) Koefisien regresi Kepemimpinan Kepala Sekolah sebesar 0,800, angka ini positif artinya setiap ada peningkatan Kepemimpinan Kepala Sekolah sebesar 0,800 point maka kinerja Guru juga akan mengalami peningkatan sebesar 0,800 point.

\section{b. Analisis Koefisien Korelasi}

Analisis koefisien korelasi dimaksudkan untuk mengetahui tingkat kekuatan hubungan dari variabel independen terhadap variabel dependen. Adapun hasil pengujian sebagai berikut:

Tabel 3. Hasil Pengujian Koefisien Korelasi Kepemimpinan Kepala Sekolah Terhadap Kinerja Guru.

Correlationsb

\begin{tabular}{llr|r} 
& & Motivasi (X1) & \multicolumn{1}{|c}{$\begin{array}{r}\text { Kinerja Karyawan } \\
\text { (Y) }\end{array}$} \\
\hline $\begin{array}{l}\text { Kepemimpinan Kepala } \\
\text { Sekolah (X) }\end{array}$ & Pearson Correlation & 1 & $.767^{* *}$ \\
\cline { 2 - 4 } & Sig. (2-tailed) & & .000 \\
\hline Kinerja Guru (Y) & Pearson Correlation & $.767^{* *}$ & 1 \\
\cline { 2 - 4 } & Sig. (2-tailed) & .000 & \\
\hline
\end{tabular}

Berdasarkan hasil pengujian diperoleh nilai korelasi sebesar 0,821 artinya Kepemimpinan Kepala Sekolah memiliki hubungan yang sangat kuat terhadap kinerja Guru.

\section{c. Analisis Koefisien Determinasi}

Analisis koefisien determinasi dimaksudkan untuk mengetahui besarnya persentase pengaruh dari variabel independen terhadap variabel dependen. Adapun hasil pengujian sebagai berikut:

Tabel 4. Hasil Pengujian Koefisien Determinasi Kepemimpinan Kepala Sekolah Terhadap Kinerja Guru.Karyawan.

\begin{tabular}{lrr|rr|r}
\multirow{2}{*}{ Model } & & \multicolumn{2}{c}{ Model Summary } \\
& $\mathrm{R}$ & & R Square & Adjusted R & \multicolumn{2}{c}{$\begin{array}{c}\text { Std. Error of the } \\
\text { Square }\end{array}$} \\
\hline 1 & $.767^{\mathrm{a}}$ & .589 & .583 & 2.700 \\
\hline
\end{tabular}

Berdasarkan hasil pengujian diperoleh nilai determinasi sebesar 0,675 artinya Kepemimpinan Kepala Sekolah memiliki kontribusi pengaruh sebesar 67,5\% terhadap kinerja Guru, sedangkan sisanya sebesar 32,5\% dipengaruhi oleh faktor lain yang tidak dilakukan penelitian.

\section{d. Uji Hipotesis}

Pengujian hipotesis dengan uji t digunakan untuk mengetahui hipotesis mana yang diterima. Rumusan hipotesis: Terdapat pengaruh yang signifikan antara Kepemimpinan Kepala Sekolah terhadap kinerja Guru.

Tabel 5. Hasil Uji Hipotesis Kepemimpinan Kepala Sekolah Terhadap Kinerja Guru.

\begin{tabular}{ll|l|l|l|l} 
Model & \multicolumn{2}{c}{$\begin{array}{c}\text { Coefficientsa } \\
\text { Unstandardized } \\
\text { Coefficients }\end{array}$} & $\begin{array}{c}\text { Standardized } \\
\text { Coefficients }\end{array}$ & & \\
& $\mathrm{B}$ & Std. Error & Beta & $\mathrm{t}$ & Sig. \\
\hline 1 (Constant) & 10.945 & 2.589 & & 4.227 & .000 \\
\hline
\end{tabular}




\begin{tabular}{l|l|l|l|l|l}
\hline Motivasi $(X)$ & .799 & .076 & .767 & 10.564 & .000 \\
\hline
\end{tabular}

a. Dependent Variable: Kinerja Guru (Y)

Berdasarkan hasil pengujian pada tabel di atas, diperoleh nilai t hitung $>\mathrm{t}$ tabel atau $(8,520>2,030$, dengan demikian hipotesis yang diajukan bahwa terdapat pengaruh yang signifikan atara Kepemimpinan Kepala Sekolah terhadap kinerja Guru diterima.

\section{PEMBAHASAN HASIL PENELITIAN}

\section{Kondisi Jawaban Responden Variabel Kepemimpinan Kepala Sekolah}

Berdasarkan jawaban responden, variabel Kepemimpinan Kepala Sekolah diperoleh ratting score sebesar 3,808 berada di rentang skala 3,40-4,19 dengan kriteria baik atau setuju.

\section{Kondisi Jawaban Responden Variabel Kinerja Guru}

Berdasarkan jawaban responden, variabel kinerja Guru diperoleh ratting score sebesar 3,889 berada di rentang skala 3,40-4,19 dengan kriteria baik atau setuju.

\section{Pengaruh Kepemimpinan Kepala Sekolah Terhadap Kinerja Guru}

Kepemimpinan Kepala Sekolah berpengaruh signifikan terhadap kinerja Guru dengan persamaan regresi $\mathrm{Y}=8,442+0,800 \mathrm{X}$, nilai korelasi sebesar 0,821 atau memiliki hubungan yang sangat kuat dengan kontribusi pengaruh sebesar 67,5\%. Pengujian hipotesis diperoleh nilai $t$ hitung $>t$ tabel atau $(8,520>2,030$. Dengan demikian hipotesis yang diajukan bahwa terdapat berpengaruh signifikan antara Kepemimpinan Kepala Sekolah terhadap kinerja Guru diterima.

\section{V.PENUTUP}

\section{Kesimpulan}

a. Variabel Kepemimpinan Kepala Sekolah diperoleh ratting score sebesar 3,808 berada di rentang skala 3,40-4,19 dengan kriteria baik atau setuju.

b. Variabel kinerja Guru diperoleh ratting score sebesar 3,889 berada di rentang skala 3,40 - 4,19 dengan kriteria baik atau setuju.

c. Kepemimpinan Kepala Sekolah berpengaruh signifikan terhadap kinerja Guru dengan persamaan regresi $\mathrm{Y}=8,442+0,800 \mathrm{X}$, nilai korelasi sebesar 0,821 atau sangat kuat dan kontribusi pengaruh sebesar 67,5\% sedangkan sisanya sebesar 32,5\% dipengaruhi faktor lain. Uji hipotesis diperoleh nilai $t$ hitung $>\mathrm{t}$ tabel atau $(8,520>2,030$.

\section{Saran}
a. Sebagai Kepala SMP Bina Bangsa di Tangerang selaku pimpinan harus lebih bijak dalam mengambil keputusan karena tidak semua keputusan dapat diterima.
b. Kemajuan suatu organisasi tidak lepas dari hubungan dan jaringan yang sangat luas oleh seorang pimpinan yang harus dimilikinya, walau tidak stand by di tempat.
c. Pimpinan tidak baik menunjukkan kemarahannya di depan publik dan harus bisa menahan emosi terhadap bawahannya agar terciptanya suasana yang kondusif.

\section{DAFTAR PUSTAKA}

Abdullah, M (2014) Manajemen dan Evaluasi Kinerja Guru, Yogyakarta: Penerbit Aswaja Pressindo. Alfabeta, Bandung.

Algifari. (2015). "Analisis Regresi untuk Bisnis dan Ekonomi”. Yogyakarta: BPFE.

Arikunto, Suharsimi (2014). "Prosedur Penelitian Suatu Pendekatan Praktek". Jakarta: 


\section{Rineka Cipta.}

Bangun, Wilson. 2012. "Manajemen Sumber Daya Manusia”. Jakarta: Erlangga

Bejo Siswanto (2013) Manajemen Tenaga Kerja Rancangan dalam Pendayagunaan dan Pengembangan Unsur Tenaga Kerja", Bandung: Sinar Baru.

Dessler, G. (2006.) Manajemen Sumber Daya Manusia (Jilid II). Jakarta: Indeks.

Edi Sutrisno (2016). Manajemen Sumber Daya Manusia. Jakarta: Prenadamedia Group.

Edwin B. Flippo (2008). "Manajemen Personalia" Jilid satu, edisi ke enam. Jakarta : Erlangga.

Fahmi Irham, 2010. "Manajemen Kinerja Teori dan Aplikasi” cetakan pertama,

George Terry R \& Rue, Leslie W. Rue (2016) Dasar-Dasar Manajemen, Jakarta Bumi Aksara.

Gerry Dessler (2016) Human Resources Management, Prenticehall, London: International Inc.

Handoko (2016) Manajemen Personalia dan Sumberdaya Manusia. Yogyakarta: BPFE.

Hasibuan, Malayu S.P. (2016). Manajemen Sumber Daya Manusia. Edisi Revisi. Jakarta: PT Bumi Aksara.

Imam Ghozali (2017). “Aplikasi Analisis Multivariate Dengan Program SPSS”. Edisi Kelima. Semarang: Badan Penerbit Undip.

Istijanto (2014) "Riset Sumber Daya Manusia". Jakarta: PT. Gramedia Pustaka

Jasmani, J., \& Sunarsi, D. (2020). The Influence of Product Mix, Promotion Mix and Brand Image on Consumer Purchasing Decisions of Sari Roti Products in South Tangerang. PINISI Discretion Review, 1(1), 165-174.

Kartini, Kartono, (2008). Pemimpin dan Kepemimpinan. Jakarta : PT. Raja

Luthans Fred (2014) Organizational Behavior, Ney York: McGraw-Hill, New York.

Mangkunegara, Prabu Anwar. (2016). Evaluasi Kinerja SDM. Cetakan ke tujuh, PT Refika Aditama: Bandung.

Nawawi, (2003). Manajemen Sumber Daya Manusia Untuk Bisnis Yang Kompetetif (edisi

2). Yogyakarta : Gadjah Mada University Press.

Robbins, P.S, \& Judge, A.T. (2003). Organizational Behavior. Jakarta: Salemba Empat.

Samsudin, Sadili (2006) "Manajemen Sumber Daya Manusia" cetakan pertama,

Santoso, Singgih (2015). "Menguasai Statistik Multivariat". Jakarta: PT Elex Media Komputindo.

Sedarmayanti (2016) Manajemen Sumber Daya Manusia, Reformasi Birokrasi dan Manajemen Guru Negeri Sipil, Cetakan Kelima, Bandung: PT Refika Aditama.

Sudjana (2014) "Metode Statistika", Bandung: Tarsido.

Sugiyono (2017), "Metode Penelitian Administrasi : dilengkapi dengan Metode R \& D". Bandung: Alfabeta.

Sujarweni V. Wiratna (2015) "Metodologi Penelitian Bisnis dan Ekonomi" cetakan pertama, Penerbit PUSTAKABARUPRESS, Yogyakarta.

Sunyoto, Danang, Cardoso (2012) "Manajemen Sumber Daya Manusia" cetakan

Veithzal Rivai (2015) Manajemen Sumber Daya Manusia Untuk Perusahaan, Jakarta: Raja Grafindo Persada.

Wahjosumidjo, (2001) "Manajemen personalia" Penerbit, Gramedia, Tangerang

Wibowo (2015) Manajemen Kinerja, Jakarta: PT. Raja Grafindo Persada.

Mogi, A. (2018). Pengaruh Kompetensi Guru, Motivasi Guru Dan Lingkungan Sekolah Terhadap Hasil Belajar Siswa SMA Tunas Indonesia Bintaro. JENIUS (Jurnal Ilmiah Manajemen Sumber Daya Manusia), 1(2).

Muslimat, A., Muhsin, H., Wahid, H. A., Yulistiana, I., Sunarsi, D., Dewi, K., ... \& Ilham, D. (2021). Develop Technology Based Multimedia For Indonesian Teachers. 
Journal of Contemporary Issues in Business and Government, 27(1), 1871-1882.

Rifuddin, B., Ilham, D., \& K, N. (2020). Academic Services in Islamic Education Management Study Program: The Actualization of the Basic Values of the State Civil Apparatus at IAIN Palopo. International Journal of Asian Education, 1(2), 8194. https://doi.org/10.46966/ijae.v1i2.34

Yuangga, K. D., Jasmani, J., \& Sunarsi, D. (2017). The Influence of Technology Determinism and Technology Literacy on Student Learning Outcomes (On MA Daarul Hikmah Pamulang). PINISI Discretion Review, 1(1), 23-30.

Sunarsi, D. (2017). Pengaruh Disiplin, Motivasi, Dan Kompetensi Terhadap Prestasi Belajar (Studi Kasus Pada Mahasiswa Universitas Pamulang, Tangerang Selatan Tahun Akademik 2016-2017). Jurnal Mandiri: Ilmu Pengetahuan, Seni, Dan Teknologi, 1(2), 207-226. 